\title{
The Impact of Housing Prices on Birth Rates in China
}

\author{
Junhan Yu \\ University of New Brunswick \\ Weiqiu Yu \\ University of New Brunswick
}

This paper explores the relationship between birth rates and housing prices in China. The empirical literature suggested mixed results in terms of relationships between housing prices and birth rates. Using a panel data of 30 provinces in China from 2002 to 2018, we estimated both static and dynamic panel models and found that there was a negative relationship between housing prices and birth rates in China from 2002 and 2018 from our dynamic model but a positive relationship from the static models. We provide some possible explanations for these findings and conclude with some policy recommendations for increasing birth rates in China.

Keywords: birth rates, housing prices, panel data, dynamic panel models, estimations, China

\section{INTRODUCTION}

Following the development of their economies and the growth of urbanization, more and more countries and regions have encountered periods of low birth rates. However, low birth rates are often accompanied by social problems, such as a sharp reduction in the working population and an aging population, which is not conducive to the sustainable development of a country in the long run. Since China's economic reform from 1978, its economy developed rapidly. The massive demographic dividend represented by its abundant labor force is one of the important explanations for this remarkable economic achievement. Currently, due to rapid changes in the nation's demographic structure over the past two generations, this dividend is gradually disappearing, and China is entering a stage of structural labor shortages (Wang, 2014).

Different countries have different mechanisms for dealing with declining birth rates. Compared with the natural decline in fertility levels in European countries, the series of rapid changes in fertility levels in China reflects significant intervention by the State. Table 1 shows a summary of China's population policy since 1949. 
TABLE 1

FERTILITY POLICY SHIFTS

\begin{tabular}{|c|c|}
\hline Policy & Time Period \\
\hline Encouragement of fertility & $1949-1953$ \\
\hline Advocacy of Family Planning & $1954-1977$ \\
\hline Selective Two-child Policy & $1978-2001$ \\
\hline Selective Two-child Policy & $2002-2015$ \\
\hline Universal Two-child Policy & $2016-2021$ \\
\hline
\end{tabular}

While State population policies have played a major role in changing China's birth rates over the past 60 years, there are many other factors that influence people's decision to have children. According to Becker's "New Family Economics" (1960), among many factors influencing people's decision to have children, family budget constraints are a major determinant. For families, housing and children are the two biggest expense items. As substitutes, the higher the housing expenditure, the less likely will people have children ( $\mathrm{Li}, 2019)$. However, housing can also be seen as a family asset. When housing prices increase, the demand for children increases (the income effect). If the income effect is greater than the substitution effect, the likelihood of having children will decrease (Dettling \& Kearney, 2014). Therefore, the impact of housing prices on birth rates depends on which effect is greater.

Since housing reform in 1998 in China, housing prices have been rising rapidly, especially in big cities such as Beijing and Shanghai. From 2003 to 2013, real housing prices grew by 13.1 percent annually in China's first-tier cities, higher than the annual growth rate of household income (Fang et al. 2015). Meanwhile, the birth rate dropped to $1.048 \%$ nationwide in 2019, its lowest point since 1949 (National Statistics Bureau). Given the sharp increases in housing prices from 2002 to 2018, the question is how significant a role housing prices play in the declining birth rates in China.

The objective of this study is to investigate the relationship between housing prices and birth rates in China by using data from 30 provinces (including autonomous regions and municipalities, except Tibet) from 2002 to 2018. The existing empirical literature on the relationship of housing prices and birth rates showed a mixed result. Some empirical studies found a positive relationship, and others a negative relationship.

In this study both static and dynamic panel data models are estimated. The results show that there was a negative relationship between housing prices and birth rates in China from 2002 and 2018 from our dynamic model but a positive relationship from the static models. We provide some possible explanations for these findings and conclude by presenting some policy recommendations.

\section{LITERATURE REVIEW}

Robinson (1997) developed an economic model of fertility based on consumer demand theory in which children, like other commodities, can be considered as a special type of capital goods. In this utility maximization model, the desire to have children stems from the demand for child-services, which can be summed up as (1) consumption utility (emotional and psychological and other non-economic benefits); (2) labour productivity utility; (3) an old-age security utility. The total child-services equals the number of children times the average quality per child. The quality of child-service is related to income, whereas the quantity is not, which means that the key factor in declining fertility in modern societies is the shift towards demand for high-quality children, who require increased external inputs (especially health and education) and internal inputs (time-consuming within the household).

As women's labor force participation and real wages increase over time, the cost of input for timeintensive child-service has risen rapidly. In modern societies, alternative sources of consumption, which can replace some of the consumption utility formerly brought by children, have emerged. All the services provided by children can be found in other markets at a price. For example, the expansion of insurance and 
social security programs has weakened the former reliance of households on children for old-age security. Given that children are a 'no-money-back' purchase, that child-services are different from child to child, and that there is some possibility of death before the household receives any services from them, the uncertainty and risk related to investment in children remain higher than is the case of other comparable household assets.

Real estate has been a steady and lucrative investment in China in the past twenty years, one that has to some extent squeezed out people's desire to have children, since people tend to invest in high return and low-cost assets. Moreover, the higher the rate of increase of housing prices, the greater is the motivation for households to devote their resources to purchasing housing rather than investing in child-rearing. From an economic point of view, people believe that they can gain easier profits from purchasing housing and then reselling it at a higher price, rather than by spending years raising a child who might not end up with a positive return. As high housing prices increasingly burden households economically, they tend to reduce investment in children--thus the decline of the birth rates.

The transition towards raising "quality" children in China means that parents tend to invest a lot of external resources in each child, to better their children's future. Given the inadequate protections provided by housing rental law in China, people who want children tend to own a house instead of renting one. Family household ownership represents an important external resource for their children. On those grounds as well, high housing prices can further hold down the birth rates.

The phenomenon of declining birth rates has attracted the attention of academics for a long time. Scholars have explored many factors affecting birth rates in the literature. Becker (1960), the founder of the field of "new family economics", pointed out that reductions in infant mortality, the popularization of contraceptive knowledge and the increase in the cost of raising children were three important factors affecting birth rates. Freedman (1995) put forward three essential explanatory variables affecting fertility rate, namely the decline in infant mortality, family planning programs, and broad social and economic development. Among them, economic development will have a negative effect on the fertility rate. The higher the degree of economic development, the faster the fertility rate will decrease. Bar \& Leukhina (2010); Jones, Schoonbroodt, \& Tertilt (2008); Schultz (2007); Wigniolle (2002) provided empirical evidence across different countries to support the "new family economics theory".

Peng (2014) used a panel data set from 1980 to 2011 in 27 regions of China and found a negative relationship between birth rates and economic development. He pointed out that economic development in Chinese cities and rural areas had different effects on birth rates: increasing urban income levels increased birth rates but rising rural income levels reduced birth rates. In addition, Happel et al. (1984) found that changes in the unemployment rate significantly affected total family income, and thus the decision-making process over reproduction. Wang (2005) argued that for China, policy implementation effect was also an important reason for large differences in fertility levels in different regions.

However, the factors affecting birth rates are very complex, and existing empirical studies have not reached consensus on this topic. Recently, some studies have shown that among the factors leading to shifts in fertility, rising housing prices play an important role. Using a provincial-level panel data set from 2000 to 2015 from China, and fixed-effect/ random-effect estimations, Jin and Liu (2019), by including the square of housing price-to-income ratios, found that housing price-to-income ratios had a positive impact on birth rates at first, and then trended negatively. That is, when the housing price-to-income ratio is low, an increase in housing price-to-income ratio will increase fertility rates; conversely, when the housing priceto-income ratio is already high, an increase in housing price-to-income ratio will bring a decrease in fertility.

$\mathrm{Li}$ (2019) attempted to explore the causal effect of housing prices on birth rates by using a city-level panel data set from 2005-2012 in China. By using difference GMM methods, the author found that both current and lagged housing prices had a significantly negative effect on birth rates. Li then revealed that it was not housing price levels generally that cause such shifts, but high rates of growth in housing prices that discouraged births. To test the exogenous shock of a housing purchase restriction policy, Li set up a difference-in-difference model (DID) and found that such a policy had a positive effect on birth rates.

Chen and Peng Yin (2016) used a time-series data set for 1990 to 2013 for China to estimate a Vector Auto Regression (VAR model) relating birth rates to housing prices to earnings ratios and child dependency 
rates. By analyzing the impulse response function and variance decomposition, they found that the strong positive response to the housing price-to-income ratio lasted for nearly 20 years, indicating that the decline in birth rates was associated with declining housing prices. Perhaps, the most relevant paper to this study was Liu, Zhang and $\mathrm{Hu}$ (2016). The authors used a panel data set of 29 provinces in China from 1999-2013 to examine the effect of housing prices on birth rates. Running regressions by gradually adding control variables, they found that housing prices had a significant negative effect on birth rates. Specifically, a $1 \%$ increase in housing prices per year was associated with a decline in birth rates of about $0.1 \%$.

Dettling and Kearney (2014) studied separately the impact of housing prices on fertility rates for those who did not own a house themselves, and that for those who did own a house. They began their empirical investigation with a set of ordinary least square (OLS) regressions. To address the possibility that other local factors could be biasing their OLS estimates, they implemented an instrumental variable (IV) strategy that exploited exogenous variations in housing prices movements induced by variation across Metropolitan Statistical Areas in their housing supply elasticity. In their view, increases in short-term housing prices increase the cost of raising children, and as a result would reduce the fertility rate proportionately among those who do not own a house. In the case of those who already own a house, however, rising housing prices to a certain extent led to the appreciation of family wealth, which has a positive overall effect on fertility. Using an US sample, they showed that for every $\$ 10,000$ increase in housing prices, the fertility rate for homeowners increased by $5 \%$, while the fertility rate of those without houses decreased by $2.4 \%$.

Easterlin and Crimmins (1985) argued that families with more members would subjectively choose housing at lower prices. They emphasized that personal preferences have an impact on birth rates, and they attribute the difference in birth rates between urban and rural areas to personal preferences. Clark, Yi and Zhang (2020) analyzed a panel data of 35 large cities from 2013 to 2017 in China and found that there was an approximately 0.94-percentage-point decrease in the probability of having a child under two with a 1 percent increase in housing prices. By conducting a panel threshold model, Su et al. (2020) found that housing prices had a negative impact on marriage when the price was above the threshold value. Homeownership is an extremely central aspect of marriage decisions in China, and marriage without housing is considered unacceptable to many.

In discussing the declining birth rates in China, Zhang (2017) pointed out that official family planning policy played a certain role in the reduction of the fertility rate in China around 1979, but it had little effect on the fertility rates after the 1990s. Jin and Liu (2019) found that the selective two-child policy (20042015) did not have a significant impact on the birth rates in China.

In summary, a lot of research has been done on the determinants of birth rates, especially for China. Population growth and increasing housing prices are two major issues in China. However, empirical studies of the impact of housing prices on birth rates to date have produced mixed results. Do changes in housing prices explain changes in birth rates in China? According to the literature reviewed, China's family planning policy and selective two-child policy had little effect on birth rates after 2000. Although it might be interesting to see how effective the universal second child policy is, the time since implementation of that policy has been too short. Due to these considerations, we decided not to include fertility policy in our analysis. This study contributes to the literature by using an updated panel data set of 30 Chinese provinces/cities from 2002 to 2018 and advanced estimation methods to estimate the relationship between housing prices on birth rates in China.

\section{DATA AND METHODOLOGY}

The microeconomic theory of fertility reviewed above hypothesized that children, like other commodities, can be considered as a special type of capital goods. In modern societies, insurance and social security can replace the function of children in parents' old-age security issues; women's labor force participation and real wage increase decrease their willingness of having children (Robinson, 1997). Birth rates also depends on other factors such as social and economic development (Becker, 1960), housing prices (Jin and Liu, 2019), and urbanization (Clark and Cummins, 2009).

Based on these studies, we next present our econometric models and variables, and data sources.

Journal of Applied Business and Economics Vol. 23(6) 2021 


\section{Model Specification}

Following the existing literature and data availability, we choose the following model to examine the determinants of birth rates in our study:

$$
B R_{i, t}=\beta_{0}+\beta_{1} \operatorname{LnHP} P_{i, t-1}+\beta_{2} \operatorname{LnGDPP}_{i, t}+\beta_{3} E D_{i, t}+\beta_{4} U R_{i, t}+\beta_{5} \operatorname{LnSSEP} P_{i, t}+\varepsilon_{i, t}
$$

In Equation (1), $B R_{i, t}$ denotes birth rates; $H P_{i, t-1}$ is the housing prices in the ith province in year $\mathrm{t}-1$; $G D P P_{i, t}$ stands for GDP per capita; $E D_{i, t}$ is women's education level; $U R_{i, t}$ is urbanization rate and $S S E P_{i, t}$ is social security per capita. $\beta_{0}$ is constant term and $\varepsilon_{i, t}$ is error term.

Most empirical studies include current housing prices or current and lagged housing prices. We follow Liu et al. (2016) by including lagged housing prices only in our study for two reasons: (1) There was a multicollinearity problem when we included both current and lagged housing prices in our model. The variance inflation factor (VIF) multicollinearity test showed that there was no multicollinearity after dropping the current housing prices from the model. (2) Lagged housing prices have a greater effect on current birth rates due to the typical 9-month pregnancy period.

Several studies (e.g., Li et al., 2019) used static models to analyze the impact of housing prices on birth rates. However, inertia in population size is a general phenomenon and can be produced by any demographic transition or perturbation (Koons, Holmes \& Grand 2007). That is, the birth rates of a certain area over a given year is greatly affected by its past birth rates. At the same time, the problem of missing important explanatory variables can be alleviated by introducing the lagged dependent variable. Therefore, in this study, we estimate both static and dynamic models in our empirical analysis. The dynamic model is as follows:

$B R_{i, t}=\beta_{0}+\beta_{1} B R_{i, t-1}+\beta_{2} L n H P_{i, t-1}+\beta_{3} \operatorname{LnGDPP} P_{i, t}+\beta_{4} E D_{i, t}+\beta_{5} U R_{i, t}+\beta_{6} \operatorname{LnSSEP} P_{i, t}+\varepsilon_{i, t}$

The newly added variable $B R_{i, t-1}$ is the birth rates in the year $\mathrm{t}-1$. Other variables have the same meaning as Equation (1).

Both our static and dynamic models may face the endogeneity problem due to possible omitted variables that could influence both the birth rates and the housing prices. For example, the culture of people having their own home and getting married in China is a factor that affects both birth rates and housing prices. Ideally, we should use some instrumental variables for our main variable of housing prices to deal with the potential endogeneity problem. For example, Binkaia \& Rudaib (2013), and Clark, Yi \& Zhang (2020) used land sales as an instrument to solve the endogeneity problem of housing prices, because land sales have a very strong influence on the housing market but do not have an obvious relationship with birth rates.

However, due to lack of land sales data, we decided to use internal instruments in our study. Anderson et al. (1982) proposed a method to provide an instrumental variable for differential dependent variable $y_{i, t-1}-y_{i, t-2}$. This instrumental variable is $y_{i, t-2}$. Since the differential variable itself contains $y_{i, t-2}$, there is a high degree of correlation between instrumental variable and endogenous variables. Given that there is no autocorrelation in the error term, there is no correlation between the instrumental and the difference of error term. Arellano and Bond (1991) argued that $y_{i, t-2}$ is not the only instrumental variable. $y_{i, t-3}$ and $y_{i, t-4}$ can also be used as instrumental variables. They proposed the first-order difference General Method of Moments (GMM) to incorporate these internal instrumental variables to solve the endogeneity problem.

\section{Variables}

Our dependent variable is Birth rates $(B R)$. Common indicators reflecting fertility levels are birth rates (BR) and total fertility rate (TFR). Following Liu, Zhang \& Hu (2016), we use the birth rates as our indicator since the total fertility rate focuses on reflecting women's fertility behavior but cannot properly reflect the 
changes in fertility caused by macro factors such as housing prices and it is difficult to obtain panel data of each province for total fertility rate (Liu et al., 2016). Independent variables are as follows.

\section{Logarithmic Housing Prices (LnHP)}

We use average sales price (yuan/square meter) of residential housing to represent our housing prices $(H P)$ which is converted into 2001 constant dollars. Housing prices as our variable of interest has different impact in different studies. Liu, Zhang \& Hu (2016) and Hui et al. (2012) argued that housing prices would have a negative effect; However, Chen \& Yin (2005), and Dettling \& Kearney (2014) showed the opposite.

\section{Logarithmic GDP Per Capita (LnGDPP)}

GDP per capita is gross domestic gross divided by population. This variable indicates the development of the economy for the sample period. The value is also converted into the 2001 price level. Bar \& Leukhina (2010); Jones, Schoonbroodt, \& Tertilt (2008) found that increases in income would reduce the fertility level. However, Peng (2014) found that increasing urban income levels would increase the birth rates but rising rural income levels would reduce the birth rates.

Education (ED), women's education level. It is calculated by the number of women over 6 years old with a high school education or above/ population over the age of 6 . Becker, Cinnirella \& Woessmann (2013) found that women's higher education was consistently associated with lower fertility. The higher the women's education level, the higher the women's participation in labor force. Having children for educated women may squeeze the time for work and thereby increase the opportunity cost of raising children. Martin (1995) found that in some of the less developed countries, education might have a positive impact on fertility.

\section{Urbanization Rate (UR)}

It is defined as the proportion of urban population in the total population (including agricultural and non-agricultural). In 2000, China's urbanization rate was $36 \%$. According to the sixth national census (November 1, 2010), the population living in cities accounted for $49.68 \%$. On the one hand, this indicator reflects the level of economic development. On the other hand, due to the large difference between rural and urban fertility rates, this indicator could control for the difference between urban and rural areas. Clark \& Cummins (2009) showed that urban women exhibit fertility rates that are, on average, 11\% lower than those of rural women in Coastal Ghana; Liu, Zhang \&Hu (2016) found there was an inverse relationship between urbanization rate and birth rates in China.

\section{Logarithmic Social Security Expenditure Per Capita (LnSSEP)}

This variable, representing the social welfare situation of different regions, includes five insurance categories: basic medical, basic pension, maternity, work injury, and unemployment. Robinson (1997) argued one of the demands for child-services is old-age security utility. As the increase of social security expenditure per capita, people tend to be less dependent on children when they are old. Liu, Zhang \&Hu (2016) found that the increase of social security expenditure per capita decreased the birth rates.

\section{Data}

China started housing market reform in 1998, we selected the period 2002-2018 because of missing data for the first few years.

The data regarding GDP per capita, housing prices and birth rates are from the CEInet Statistics database. Social security expenditures per capita are calculated based on the data from the China Labor Statistics Yearbook; the data on urbanization rates are from China Statistics Yearbook; the data on women's educational levels are calculated based on the China Population and Employment Statistical Yearbook. Due to the missing data on women's education levels in the year 2010, we conducted the method of linear interpolation to fill in the missing data.

With our panel data set, we first need to test the stationarity of the variables before fitting the model. Non-stationary time series may appear in the following three situations: deterministic trends, structural 
changes, and random trends. Non-stationary time series will cause the traditional t-test to fail and lead to spurious regression. To avoid spurious regression, we conducted stationarity tests for each variable using the Levin-Lin-Chu (LLC) and Im-Pesaran-Shin (IPS) panel data unit root tests for all variables. The results in Table 3 show that all variables are stationary except UR, LnGDPP and LnSSEP. After first order differencing, both are stationary. Thus, we replaced them by their first differences in the regressions,

TABLE 2

PANEL UNIT ROOT TESTS

\begin{tabular}{|c|c|c|}
\hline Variables & LLC & IPS \\
\hline$B R$ & $-3.892^{* * *}$ & $-2.565^{* * *}$ \\
\hline $\operatorname{LnHP}$ & $-7.243^{* * *}$ & $-3.210^{* * * *}$ \\
\hline LnGDPP & 0.065 & 6.654 \\
\hline$E D$ & $-5.538^{* * *}$ & $-4.777^{* * *}$ \\
\hline$U R$ & -0.705 & $-1.95^{* *}$ \\
\hline LnSSEP & -0.267 & 1.775 \\
\hline$D U R$ & $-10.822^{* * *}$ & $-10.589^{* * *}$ \\
\hline$D L n G D P P$ & $-5.176^{* * *}$ & $-6.980^{* * *}$ \\
\hline DLnSSEP & $-3.826^{* * *}$ & $-9.952^{* * *}$ \\
\hline
\end{tabular}

Note: ${ }^{* * *},{ }^{* * *}$ indicated it is significant at the level of $10 \%, 5 \%$ and $1 \%$.

\section{RESULTS}

We first estimate the static model by using Pooled Ordinary Least Square (POLS), Fixed Effect (FE), Least Square Dummy Variable (LSDV) and Random Effect (RE). POLS is still unbiased and consistent if errors are serially correlated but POLS will not be efficient anymore (Wooldridge, 2015). Considering each province is unique, we believe that there exists a province-specific idiosyncratic effect. To examine the individual effect, we run an FE model without robust standard error. The F-test shows that FE is significantly better than Pooled OLS. However, since cluster robust standard errors are not used, this F test is not effective because ordinary standard errors are only about half of cluster robust standard errors. Therefore, we further run LSDV and found that most of the individual dummy variables are significant, that is, we believe that there are individual effects, and FE is better than Pooled OLS.

To determine whether FE or RE is more appropriate, we conducted a Hausman test showing that the null hypothesis was rejected, so FE is better than RE. We then conducted heteroskedasticity, autocorrelation and cross-sectional correlation tests and found that all three problems exist. Therefore, in the end we used Feasible Generalized Least Squares (FGLS) estimation method as our final static estimations. The results of all regressions are reported in Table 3.

TABLE 3

REGRESSION RESULTS OF THE STATIC PANEL DATA MODEL

\begin{tabular}{lccccc}
\hline \multicolumn{1}{c}{ Variable } & OLS & FE & LSDV & RE & FGLS \\
\hline \multirow{2}{*}{ L.LnHP } & $0.843^{* *}$ & 0.364 & 0.364 & $0.419^{*}$ & $\mathbf{0 . 6 0 5}$ \\
& $(1.013)$ & $(0.222)$ & $(0.021)$ & $(0.221)$ & $\mathbf{( 0 . 1 6 0 )}$ \\
ED & $-0.273^{* * * *}$ & 0.009 & 0.009 & -0.009 & $\mathbf{- 0 . 0 0 1}$ \\
\multirow{2}{*}{ DUR } & $(0.107)$ & $(0.032)$ & $(0.050)$ & $(0.031)$ & $\mathbf{( 0 . 0 1 2 )}$ \\
& 0.011 & -0.004 & -0.004 & $-0.004^{*}$ & $\mathbf{- 0 . 0 0 9 *}$ \\
DLnGDPP & $(0.012)$ & $(0.010)$ & $(0.007)$ & $(0.010)$ & $\mathbf{( 0 . 0 0 3 )}$ \\
& -0.475 & $1.488^{*}$ & 1.489 & 1.292 & $\mathbf{- 0 . 1 0 3}$ \\
& $(1.457)$ & $(0.902)$ & $(0.903)$ & $(0.907)$ & $\mathbf{( 0 . 3 1 9 )}$ \\
\hline
\end{tabular}




\begin{tabular}{lccccc}
\hline DLnSSEP & 0.109 & $-0.505^{* *}$ & -0.505 & -0.492 & $\mathbf{0 . 0 8 5}$ \\
& $(0.121)$ & $(0.536)$ & $(0.336)$ & $(0.540)$ & $(\mathbf{0 . 1 0 7 )}$ \\
Constant & $7.843^{* * *}$ & $8.182^{* * *}$ & 4.213 & $7.962^{* * *}$ & $\mathbf{2 . 3 2 3}^{*}$ \\
Obs & $(2.557)$ & $(1.528)$ & $(2.851)$ & $(1.586)$ & $\mathbf{( 1 . 4 5 6 )}$ \\
\hline
\end{tabular}

Note: $^{*},{ }^{* *},{ }^{* * *}$ indicates significance at the level of $10 \%, 5 \%$ and $1 \%$ respectively.

Table 3 shows that the lagged housing prices is significant at the $1 \%$ level of significance in FGLS. It is shown that there was a positive relationship between lagged housing prices and birth rates which is in contrast with that of Liu et al. (2016). Although this result could be interpreted as the wealth (home equity) effect outweighed the negative substitution effect, we believe our static model estimations might be biased due to the potential endogeneity problem mentioned above. Liu et al. (2016) included the lagged birth rates to alleviate the endogeneity. To deal with this problem, we set up our GMM model by including lagged birth rates and internal instruments.

Due to lack of external instruments, we decided to use Difference Generalized Method of Moments (GMM) that includes lagged dependent housing prices as internal instruments. The prerequisite for establishment of the difference GMM is that there is no autocorrelation in the disturbance term. Furthermore, it also possible that the difference GMM may generate too many internal instruments resulting in an overidentification problem. To deal with these issues, we conducted autocorrelation test and the Sargan test for overidentification. This model passed both tests. The results of our difference GMM are presented in Table 4.

TABLE 4

REGRESSION RESULTS OF DYNAMIC PANEL DATA MODEL

\begin{tabular}{|c|c|}
\hline Variable & Difference GMM \\
\hline L.LnBR & $\begin{array}{c}-0.124^{* * *} \\
(0.040)\end{array}$ \\
\hline L.LnHP & $\begin{array}{c}-0.600^{* * *} \\
(0.191)\end{array}$ \\
\hline ED & $\begin{array}{c}0.087 * * * \\
(0.014)\end{array}$ \\
\hline DUR & $\begin{array}{l}-0.005^{*} \\
(0.002)\end{array}$ \\
\hline DLnGDPP & $\begin{array}{l}0.229^{*} \\
(0.137)\end{array}$ \\
\hline DLnSSEP & $\begin{array}{c}0.015 \\
(0.124)\end{array}$ \\
\hline Constant & $\begin{array}{c}16.433^{* * *} \\
(1.595)\end{array}$ \\
\hline Obs & 450 \\
\hline
\end{tabular}

Note: $* * * *$ indicated it is significant at the significance level of $10 \%$ and $1 \%$.

Table 4 shows that the lagged birth rates had a significant and negative impact on the current birth rates. At the same time, the lagged housing prices had a negative relationship with birth rates, which is statistically significant at the $1 \%$ level. This negative relationship is consistent with Liu et al. (2016). We feel more confident with our difference GMM model because it alleviates the endogeneity problem by including lagged birth rates and internal instruments. The results from the difference GMM showed that if lagged housing prices increased by $1 \%$, other variables being constant, birth rates decreased by $0.6 \%$. Meanwhile, the results also show that the higher the women's education level, the higher the birth rates. Martin (1995) 
indicates that in some less developed countries, women's education might have a positive impact on fertility. From the result of difference GMM the growth of urbanization rate is statistically significant negative to the birth rates at the $10 \%$ level of significance, which is consistent with the findings of Guo et al. (2012). The growth of GDP per capita has a positive effect on birth rates at 10\% significant level. Here we use the growth of GDP per capita, which is different from the GDP per capita that some other researchers used. Thus, our conclusions may differ. As an indicator of economic development, with higher growth of GDP per capita, people are more likely to have children. Our result showed that, as the growth of GDP per capita increased by $1 \%$, birth rates increased by $0.229 \%$. In the household theory of fertility, there are two effects in consumption of child- service. One is income effect, that is, higher income allows for larger family size; the other is substitution effect, that is, higher price (cost) of children implies smaller family size. Here we tend to believe that the income effect dominates the substitution effect.

\section{CONCLUSIONS AND POLICY RECOMMENDATIONS}

This study attempted to investigate the relationship between birth rates and housing prices in China. The theoretical literature suggested that family size depends on the net effect of income effect and substitution effect. The results from empirical studies have shown mixed results in terms of relationships between birth rates and housing prices. We followed the existing literature by setting up a theoretical model which suggests that the relationship between birth rates and housing prices depends on other consumption expenditures (except housing) and family wealth. Then we estimated both static and dynamic panel data models by using several estimation methods, including Feasible Generalized Least Square (FGLS) estimation of a Fixed Effect (FE) static model and Difference Generalized Moment Method (GMM) with a dynamic model to estimate the relationship between birth rates and housing prices in China from 30 provinces (including autonomous regions and municipalities, except Tibet) from 2002 to 2018. The results showed that there was a negative relationship between housing prices and birth rates in China from 2002 and 2018 in our Difference GMM model.

Furthermore, our findings show that the higher the rate of growth of urbanization, the lower the birth rates. Because consumption levels in urban area are greater than those in rural areas, people who have just entered the city may face greater economic pressure. Since children are an expensive commodity, at least in the short term, increases in housing prices will push the new migrants to put off having children, resulting in lower birth rates. As is shown in our Difference GMM model, the growth rate of GDP per capita has a positive effect on birth rates.

As for policy recommendations, given the negative relationship between housing prices and birth rates, it is necessary to introduce policies and administrative measures to regulate and control skyrocketing housing prices. Perhaps the most urgent need for the government is to reduce the cost of "first homes". At present, excessively high housing prices have increased the pre-purchase savings rate of the "first home" people, while at the same time increasing their post-purchase debt-asset ratio, which puts them under tremendous financial pressure. At the same time, the "first home" groups are mainly composed of young people, who are the main contributors to rises in birth rates. In terms of specific measures, we believe that, on the one hand, the government should introduce preferential policies for the "first home" group, such as preferential housing loans for their first homes. On the other hand, officials should develop plans for discouraging speculative housing demand to reduce overall housing prices. The government can increase the minimum down payment percentage for second homes, levy real estate taxes, etc.

Like most empirical studies, this study has limitations. The key limitation of this study is that we relied on internal instruments contained in the difference GMM model to deal with the potential endogeneity problem. For future studies, external instruments could be introduced to improve our results. 


\section{REFERENCES}

Anderson, T.W., \& Hsiao, C. (1982). Formulation and estimation of dynamic models using panel data. Journal of Econometrics, 18(1), 47-82.

Arellano, M., \& Bond, S. (1991). Some tests of specification for panel data: Monte Carlo evidence and an application to employment equations. The Review of Economic Studies, 58(2), 277-297.

Bar, M., \& Leukhina, O. (2010). Demographic Transition and Industrial Revolution: A Macroeconomic Investigation. Review of Economic Dynamics, 13(2), 424-451.

Becker, G.S. (1960). An Economic Analysis of Fertility, Demographic and economic change in developed countries: A conference of the Universities. National Bureau Committee for Economic Research, 209.

Becker, S.O., Cinnirella, F., \& Woessmann, L. (2013). Does women's education affect fertility? Evidence from pre-demographic transition Prussia. European Review of Economic History, 17(1), 24-44.

Binkaia, C., \& Rudaib, Y. (2013). Land Supply, Housing Price and Household Saving in Urban China: Evidence from Urban Household Survey. Economic Research Journal, 1, 1-22.

Chen, S. (2016). Housing affordability, fertility behavior and population age structure. China Population News, 2016(7), 18003.

Clark, G., \& Cummins, N. (2009). Urbanization, mortality, and fertility in Malthusian England. American Economic Review, 99(2), 242-47.

Clark, W.A., Yi, D., \& Zhang, X. (2020). Do House Prices Affect Fertility Behavior in China? An Empirical Examination. International Regional Science Review, 0160017620922885.

Dettling, L.J., \& Kearney, M.S. (2014). House prices and birth rates: The impact of the real estate market on the decision to have a baby. Journal of Public Economics, 110, 82-100.

Easterlin, R.A., \& Crimmins, E.M. (1985). The fertility revolution: A supply-demand analysis. University of Chicago Press.

Fang, H., Gu, Q., Xiong, W., \& Zhou, L. (2015). Demystifying the Chinese Housing Boom. NBER Working Paper No. 21112. Cambridge, MA: NBER.

Freedman, R. (1995). Asia's recent fertility decline and prospects for future demographic change.

Guo, Z., Wu, Z., Schimmele, C.M., \& Li, S. (2012). The effect of urbanization on China's fertility. Population Research and Policy Review, 31(3), 417-434.

Happel, S.K., Hill, J.K., \& Low, S.A. (1984). An economic analysis of the timing of childbirth. Population Studies, 38(2), 299-311.

Hui, E.C., Zheng, X., \& Hu, J. (2012). Housing price, elderly dependency and fertility behaviour. Habitat International, 36(2), 304-311.

Jin, T., \& Liu, D. (2019). The Impact of Housing Prices on the Birth Rate of Urban Population: An Analysis Based on China's Provincial Panel Data. Shandong Social Sciences, 1, 176-181.

Jones, L.E., Schoonbroodt, A., \& Tertilt, M. (2008). Fertility theories: Can they explain the negative fertility-income relationship? (No. w14266). National Bureau of Economic Research.

Koons, D.N., Holmes, R.R., \& Grand, J.B. (2007). Population inertia and its sensitivity to changes in vital rates and population structure. Ecology, 88(11), 2857-2867.

Li, J. (2019) Did high housing prices lower the birth rate? - Analysis based on the theory of new family economics. Nankai Economic Research, (4), 58-80.

Liu, X., Zhang, J., \& Hu, Y. (2016). The impact of rising housing prices on the birth rate: An empirical study based on China's 1999-2013 data. Journal of Chongqing University of Technology (Social Sciences), 3001, 53-61.

Martin, T.C. (1995). Women's education and fertility: Results from 26 Demographic and Health Surveys. Studies in Family Planning, pp. 187-202.

Peng, H., \& Meng, X. (2014). Declining birth rate and economic development in China. Statistical Research, (9), 44-50.

Robinson, W.C. (1997). The economic theory of fertility over three decades. Population Studies, 51(1), 63-74. 
Schultz, T.P. (2008a). Population Policies, Fertility, Women's Human Capital, and Child Quality. In Handbook of Development. Yale University.

Su, C.W., Khan, K., Hao, L.N., Tao, R., \& Peculea, A.D. (2020). Do house prices squeeze marriages in China? Economic Research-Ekonomska Istraživanja, 33(1), 1419-1440.

Wang, J., Wang, Z., He, Y. (2005). Analysis on the Socio-economic Influencing Factors of the Differences in the Fertility Level of Women in Various Regions in China. Southern Population, (2), 31-39.

Wang, Z. (2014). China's "labour shortage" and migrant workers' lack of social security. International Labour Review, 153(4), 649-658.

Wigniolle, B. (2002). Fertility, intergenerational transfers and economic development. Journal of International Trade \& Economic Development, 11(3), 297-321.

Wooldridge, J.M. (2015). Introductory econometrics: A modern approach. Cengage learning.

Yi, J., \& Zhang, J. (2010). The effect of house price on fertility: Evidence from Hong Kong. Economic. 